\title{
Chemical Engineering Principles for Intensification of Domestic Operations
}

\author{
Sunil J. Kulkarni* \\ Gharda Institute of Technology, Lavel, Khed.India.
}

*Corresponding Author: Sunil J. Kulkarni, Gharda Institute of Technology, Lavel, Khed.India.

\begin{abstract}
The unit operations and unit processes in chemical engineering along with mechanical operations are part of our life. If we consider our body as a chemical plant then it has all the operations including size reduction, energy synthesis, membrane separations, mass transfer, heat transfer and conveyers. Day to day processes like tea preparation, cooking, cutting resembles various size reduction and unit operations. Tea making is solid liquid extraction, called as leaching. The equilibrium exists between the solute present in the solid phase and liquid phase. The principle of diffusion exists in fragrance, scent, deodorant, mosquito killers. Washing of cloths also involves chemistry. Chemical engineering principles have huge potential in domestic applications. In processing of food grains, rice, chemical engineering principles play very important and significant role. This paper discusses the applications of unit operations for optimization of cloth drying, rice preparation and cooking, tea making and other domestic processes. Intensification refers to increasing efficiency, conversion, yield and reducing the space requirement and cost for the process. Domestic processes can be intensified by using various chemical engineering fundamentals
\end{abstract}

Keywords: Processes, operations, brewing, moisture, drying, extraction.

\section{INTRODUCTION}

Many domestic process and methods used for cooking, washing, cleaning involves chemical engineering principles. Chemical engineering is interdisciplinary field in which many mechanical operations, chemistry fundamentals, kinetics, isotherms studies, unit operations and heart transfer operations are involved. Almost all the products which we use in our day to day life are produced by chemical engineering principles. Investigations are carried out to optimize the operations like cloth drying, cooking, and cloth washing by applying chemical engineering principles. This paper discusses the applications of unit operations for optimization of cloth drying, rice preparation and cooking, tea making and other domestic processes.

\section{Chemical ENGINEERING}

Chemical engineering is application of physiochemical principles for transformation of the raw material into product by bringing about change in composition, energy content or physical state by processing it. Almost all the products starting from shaving cream, tooth paste, brush,soap, detergent, cloths, polyethylene bags, plastic, footwear, mattress etc. are prepared by chemical engineering principles. Powerful methodology is core of chemical engineering (1). Chemical engineer analyzes, designs and operates the processes in solid, liquid and gaseous phase (2). This requires strong knowledge of chemistry and physical principles. Process calculation is fundamental subject in chemical engineering which introduces to the chemical engineering processes and unit operations. Material and energy balances with relevant physical and chemical principles are learnt in this subject (3-4). Heat transfer operation and solid fluid mechanical operations are interdisciplinary subjects also covered in chemical engineering (5-7). Chemical reactions are part of many processes. Studies on conversion, yield, reaction mechanism, design of reactor are learnt in chemical reaction engineering (8-9). Environmental engineering in interdisciplinary subject also studied in chemical engineering with focus on industrial pollution control (10).

\section{Chemical Engineering in DOMESTIC APPlications}

Chemical engineering finds many applications in our daily life. The unit operations and unit processes in chemical engineering along with mechanical operations are part of our life. If we consider our body 
as a chemical plant then it has all the operations including size reduction, energy synthesis, membrane separations, mass transfer, heat transfer and conveyers. Day to day processes like tea preparation, cooking, cutting resembles various size reduction and unit operations. Tea making is solid liquid extraction, called as leaching. The equilibrium exists between the solute present in the solid phase and liquid phase. More gradual is the heating; the equilibrium concentration is more. Cooking of the rice in the cooker is one more example of equilibrium operation. The cooking happens at the typical pressure when the moisture content reaches equilibrium value. Also preparation of cooked vegetable food involves such principles. The principle of diffusion exists in fragrance, scent, deodorant, mosquito killers. Washing of cloths also involves chemistry. Chemical engineering principles have huge potential in domestic applications. In processing of food grains, rice chemical engineering principles play very important and significant role.

\section{INVESTIGATIONS}

\subsection{Tea preparation}

Akhtaruzzaman etal. carried out investigation on drying of tea in fluidized bed dryer(11). They studied drying curve and drying characteristics. It took only 20 minutes for them to dry the material by 65 percent. According to them, current practice of using perforated trays and hot air, results in hardening of tea. In such case the particles becomes hard from outside but contains some moisture. For this reason, use of fluidized bed for tea drying is advocated. They identified two falling rate periods for the drying process. Yang et.al. investigated tea infusion by using different diffusion models (12).Various compounds and elements present in the tea influence the diffusion of tea. There are many elements in tea which have positive health effects such as catechines, gallic acid and caffenine, which needs to be diffused in water in sufficient quantity (13). In case of black tea fermentability of the tea cultivator is used for getting maximum effects (14). In case of black tea, the safe transport of tea is important. The moisture content of black tea must be maintained between 2 to 9 percent.

Tea is hygroscopic and it has tendency to absorb or desorb moisture in response to the environmental variations (15). Babin et al. analyzed instant tea brewing system for multiple heat transfer (16). They carried out experimental and theoretical analysis for three processes identified by them. The first process is heating of tap water by the coils. The flow of hot water through transition tubes was identified as second process (16). Dripping of brewed tea in to the decanter was third process. They found that the experimental and analytical results were in close agreement with each other. The extraction of caffeine and theaflavins from tea leaves was investigated by Price (17). He used two phase model for explaining the data. The kinetic studies for the swollen leaf and aquatic phase indicated first order kinetics. They found that the $\mathrm{pH}$ and salt content affects differently on caffeine and theaflavins. The extraction of earlier was affected by ion concentration and not the $\mathrm{pH}$, the later was $\mathrm{pH}$ dependent. Tea origin also has significant effect on extraction dynamics.

\subsection{Cloth Drying}

Drying of cloth is very common domestic practice. Cloths are normally dried in sunlight and blowing wind takes away moisture. These phenomenon of drying works onthe two principles. First is evaporation. When the cloths are exposed to higher temperature, evaporation occurs. Mainly free moisture is evaporated at very fast speed. The second principle is drying. Typically the moisture is carried with the dry air, increasing humidity of air. Thus the movement of moisture from interior surface to the outer surface becomes important factor. In the region with very high humidity, the cloths doesn't dry, even at very high temperature. There exists an equilibrium in typical drying operations. This equilibrium is between the moisture present in the solid and moisture present in the air. Dryers use the dry air for drying. The air used for drying in high end applications is free of moisture. Also as amount of residual moisture reduces, the degree of difficulty also goes on increasing since the moisture to be removed is bound moisture and the moisture present in interior part of the cloths or solids. There is certain equilibrium moisture for certain humidity condition. Calculation of time required for drying is done with the help of time verses moisture data. The initial removal of moisture is constant and termed as constant rate period. Then the falling rate period occurs. Nowadays cloth drying has become confined to indoor space (18). Also humidity of indoor air increases and the environment inside the room is affected. In humid climate, like in Mumbai, the air conditioner is required for almost eight months a year. So indoor drying of air becomes almost impossible. This presents opportunity to use the hot air from exhaust for cloth drying. Many such investigation indicate 
that this approach of using hot air of air conditioners is feasible (19-21). Suntivarakorn et al. carried out investigation on use of hot air of split air conditioners for cloth drying (18). They used fan at the air exit to avoid obstruction. This actually increases the power consumption. Their studies indicated that the drying without fans is also practical with some modifications in wall of the drying chamber.

Cloths play important role in control of our body temperature and physiological processes involved in the same (22). Convectional and evaporative heat transfer between the skin and the cloth happens. The earlier one depends on the temperature difference between skin, cloth and the air surrounding the systems. The evaporative process depends on the vapour pressure and the permeation and insulation of the clothing along with sweat production (22). The heat transfer between the cloths and atmosphere is mainly convective heat transfer. Many investigations are reported on modelling of the heat and moisture transfer through clothing (23-25). Phase change in evaporation and condensation along with convective and diffusion transfer mechanisms are important aspect of modelling. Steady state models are proposed by many investigators. Accumulation of water happens in the process. It was deemed necessary by many investigators to consider this aspect of the process while modeling. Many investigators have worked on modeling of these heat and mass transfer processes (26-28).

Shen et. Al. developed heat pump cloth dryer (HPCD) (29).The heat pump with an evaporator, compressor condenser and an expansion valve was used by them. In evaporator, the processed air is fed where takes away moisture. Then it is compressed and condensed. This air is heated due to coming in contact with refrigerant.

\subsection{Rice Production and Cooking}

Artificial rice production from local materials can solve the food security problems in countries having the food problem. The development of artificial rice is complex process. Stirring, printing and ripening of rice can be carried out in one step by using extrusion cooking (30). Santoso et al. developed extruder for obtaining such rice from domestically available raw corn and cassava mocaf (30). Many investigations have been carried out for use of different extrusion methods for artificial rice production(31-32).Temperature, screw speed and dough moisture content are important factors in the process of extrusion(32). Solar energy is available in abundance in tropical countries. This energy can be utilized for domestic applications in tropical countries. Parabolic trough collector was used for the rice cooking by Mohan and Vasathakumar (33).In steam cooking the rice is kept away from water and brought in contact with steam. Steam cooked food contains less fats. Steaming provides more nutritional value than the boiling. Low pressure steaming can be used in two ways. Direct steaming is carried out in a pan of boiling water. Indirect steaming is carried out on two plates over a pan of boiling water (33).In high pressure steaming, steam is not allowed to escape. They observed that concentration of energy on the aluminum sheet was more intense. Cooking and eating qualities of milled rice were studied and survey of literature was done by Juliano et al. (34). Characteristics of the cooked rice needs to be considered carefully while analyzing various cooking methods.

\section{CONCLUSION}

The unit operations and unit processes in chemical engineering along with mechanical operations are part of our life. If we consider our body as a chemical plant then it has all the operations including size reduction, energy synthesis, membrane separations, mass transfer, heat transfer and conveyers. Day to day processes like tea preparation, cooking, cutting resembles various size reduction and unit operations. Intensification refers to increasing efficiency, conversion, yield and reducing the space requirement and cost for the process. Domestic processes can be intensified by using various chemical engineering fundamentals.Chemical engineering principles have huge potential in domestic applications. In processing of food grains, rice chemical engineering principles play very important and significant role.

\section{REFERENCES}

[1] Sargent, Roger, What is chemical engineering?.AIChE national meeting, At Chicago https://www. researchgate. net/ publication /272091837, 1-7, 1990.

[2] M. J. McCready,Engineering, Chemical Engineering, the Chemical Engineering Curriculum and Careers for Chemical Engineers, june 1999https:// www 3.nd.edu > mjm > chegs_cheg. careers.pdf, 1-26, 1999.

[3] B. L. Bhatt, S.M. Vora,Stoichiometry, 4th Edition, Tata McGraw-Hill, 2004.

[4] K.V.Narayanan, B.Lakshmipathy, Stoichiometry and Process Calculation, PHI Learning Ltd, 2013. 
[5] S. J. Kulkarni,Chemical Engineering - an Insight into the Fundamentals and Interdisciplinary Approach, International Journal of Recent Technology and Engineering, Vol.8,No.1, 1322-1326, 2019.

[6] TreybalR.E.(1992). Mass Transfer Operations. McGraw Hill 3rd Edition, pp. 565-645.

[7] Y. A. Cengel, Heat Transfer, Third ed. McGraw-Hill, Chaleur - Transmission - 901 pages, 2007.

[8] J.M.Smith,Chemical Reaction Engineering, 3rd ed., TataMcGraw Hill, 1980.

[9] H.S. Fogler, Elements of Chemical Reaction Engineering, 4ed, PHI, 2008.

[10] S.P.Mahajan, Pollution Control in Process Industries. Tata-McGraw Hill, New Delhi, 1985.

[11] M. Akhtaruzzaman, M. R. Ali, M. M. Rahman, M. S. Ahamed, Drying Tea in a Kilburn Vibro Fluid Bed Dryer. J. Bangladesh Agril. Univ. Vol.11, No.1, pp. 153-158, 2013.

[12] D.J. Yang, C.C. Hu, J.-T. Lin, Kinetics of Short-Time Tea Infusion Using A Diffusion Model. Chung Shan Medical Journal, Vol. 25, pp. 31-39, 2014.

[13] J.K.Llin, C.L. Lin, Y.C. Liang, S.Y. Lin-Shiau, I.M.Juan.Survey of Catechins, Gallic Acid, and Methylxanthiens in Green, Oolong, Pu-Erh, and Black Teas. Journal of Agricultural and Food Chemistry, Vol.46, pp.3635-3642, 1998.

[14] P.K. Mahanta Biochemical Analysis as a Measure of Dynamic Equilibrium in Genomic Setup During Processing of Tea. J. Biosci., Vol. 13, No.3, pp.343-350, 1988.

[15] P. Dmowski, M. Ruszkowska. Equilibrium Moisture Content Importance in Safe Maritime Transport of Black Tea. Vol. 12, No.2, pp.399-404, 2018. Doi: 10.12716/1001.12.02.22

[16] B. A. Babin, G. Gilzow, L. Guerrero-Gonzalez, X. Fan. Multiple Heat Transfer Processes ofa Tea Brewing System: Theoretical And Experimental Investigations, Proceedings Of The 2010 ASEE Gulf-Southwest Annual Conference, Mcneese State University Copyright (C) 2010, American Society For Engineering Education, pp.1-10, 2010.

[17] W.E.Price.Kinetics and Equilibria of Tea Infusion. A Thesis Submitted for The Degree of Doctor of Philosophy ofthe University of London andfor The Diploma of Membership of Imperial College Department of Chemistry Imperial College London October 1985, pp.1-260, 1985.

[18] P. Suntivarakorn, S. Satmarong, C. Benjapiyaporn, S. Theerakulpisut. An Experimental Study on Clothes Drying Using Waste Heat from Split Type Air Conditioner. World Academy of Science, Engineering and Technology International Journal of Mechanical and Mechatronics Engineering, Vol.3, No.5, pp. 483-488, 2009.

[19] V. Yadav and C. G. Moon. Modelling and Experimentation for the Fabric-Drying Process in Domestic Dryers. Applied Energy, Vol. 85, pp.80-95, 2008.

[20] A. B. Ng and S. Deng. A New Termination Control Method for A Clothes Drying Process in A Clothes Dryer. Applied Energy, Vol.85, pp. 818-829, 2008.

[21] J. Deans. The Modeling of a Domestic Tumbler Dryer.Applied Thermal Engineering,Vol.21, pp.977-900, 2001.

[22] C. Voelker, S. Hoffmann, O. Kornadt, E. Arens, H. Zhang, C. Huizenga.Heat and Moisture Transfer through Clothing.Eleventh International IBPSA Conference Glasgow, Scotland July 27-30, pp. 1360-1365, 2009.

[23] B. Farnworth.A Numerical Model of the Combined Diffusion of Heat and Water Vapor through Clothing. Textile Research Journal, 56 (11), pp.653-665, 1986.

[24] P.S.H.Henry.Diffusion in Absorbing Media. Proceedings of the Royal Society of London. Series A, Mathematical and Physical Sciences, Vol.,171, No.945, pp.215-241, 1990.

[25] Y. Ogniewicz, C.L. Tien. Analysis of Condensation in Porous Insulation.International Journal of Heat and Mass Transfer, Vol.24, No.(4, pp. 421-429, 1981.

[26] X. Xu, J. Werner, J. (1997). A Dynamic Model of the Human/Clothing/Environment-System. Applied Human Science, Vol.16, No.2, pp.61-75, 1997.

[27] J. Fan, J. X. Cheng. Heat and Moisture Transfer with Sorption and Phase Change through Clothing Assemblies. Textile Research Journal, Vol.75, No.3, pp.187-196, 2005.

[28] Y..Li, B.V. Holcombe. Mathematical Simulation of Heat and Moisture Transfer in a Human-ClothingEnvironment. Textile Research Journal, Vol.68, No.6, pp.389-397, 1998.

[29] B. Shen, K. R. Gluesenkamp, P. Bansal, D. Beers. Heat Pump Clothes Dryer Model Development. International Refrigeration and Air Conditioning Conference. Paper 1755, pp.1-10. Http://Docs.Lib.Purdue.Edu/Iracc/1755, 2016

[30] A. Santoso, Y. Wibisonoo, B. Poerwanto, A.S.S. Didiek. Development Process Based on Healthy Artificial Rice by using Local Tuber Single Screw Extruder. International Journal of Advance Engineering and Research Development, Vol.5, No.2, pp.1186-1190, 2018. 
[31] C. Mouquet, B. Salvignol, N. Van Hoan, J. Monvois, S. Treche. Ability of a "very low cost extruder" to produce instant infant flour at a small scale in Vietnam. Food Chem. Vol. 82,pp. 249-255, 2003.

[32] R.Guy,Extrusion Cooking, Technologies and Applications. Woodhead Publishing Limited, Cambridge England, 2003.

[33] B. Mohan, D. Vasanthakumar.Analysis of the Effectiveness of Solar Assisted Steam Cooking using Parabolic Trough Collector. International Research Journal of Engineering and Technology, Vol. 2, No. 40, pp.932-939, 2015.

[34] B.O. Juliano.An International Survey of Methods used for Evaluation of the Cooking and Eating Qualities of Milled Rice Rice.International Rice Research Institute, Los Bafios, Laguna, Philippines. Submitted To The Irri Research Paper Series December 1981.Irs No. 77. pp.1-29, June 1982.

Citation: Sunil J. Kulkarni, "Chemical Engineering Principles for Intensification of Domestic Operations”, International Journal of Advanced Research in Chemical Science, 7(2), pp. 11-15. DOI: http://dx.doi.org/10.20431/2349-0403.0702003

Copyright: (C) 2020 Authors, This is an open-access article distributed under the terms of the Creative Commons Attribution License, which permits unrestricted use, distribution, and reproduction in any medium, provided the original author and source are credited. 